\title{
Conservation and protection of the Bosnian kingdom: medieval military fortifications and interventions on it
}

\author{
L. Kudumović, A. Čaušević, N. Rustempašić \& N. Kuljuh \\ Faculty of Architecture, Sarajevo, Bosnia and Herzegovina
}

\begin{abstract}
Bosnia is a historical name of the present Bosnia and Herzegovina, the Balkan country which has existed in various constitutional forms for around 1000 years. Development of Bosnian cities is a reflection of different influences through history. This paper is focused on remains of medieval time and fortification objects. Fortresses are symbols of various things for various peoples, but also are part of collective identity, much more than just military fortified structures. There is something inherently, compelling, and mystified by intrigue and drama, curiosity, loneliness, past and its impact on our present inside the ruins and remnants of old fortifications. They create a sense of hope despite their decay. After heritage has been evaluated to have outstanding significance its usage in future must be defined. According to the result of numerous studies conducted in this field of scientific work, evident is the necessity for a systematic approach that can be characterized as the inevitability of the existence of management plans. Causes of collapses of medieval forts are various and they range from insufficient tensing capacity, "economical aspect" of original structure, level of technical culture of that time, "extended" duration of the facility, mistakes made while creating the original design, to the inevitable wear-and-tear process (results from physical-chemical changes of properties of materials). As well, it is necessary to consider following possible changes that occurred during time in: surrounding, purpose of a facility, ground (excavation, change of water level), and certainly, in structure itself (addition, partial demolition etc.). Intervention on the monument involves finding a reasonable and acceptable restoration solution that is going to lead to recovery and respect the value of the historical monument at the same time.
\end{abstract}

Keywords: masonry, mechanical properties of materials, fortresses, fortification, stability, intervention. 


\section{Introduction}

There is something inherently, tempting and mystified in the ruins and remains of old fortresses. Questions that are logically imposed at the first sight with these witnesses of the past are related with their condition, age and role in the history, data about their builders, architects, owners and employers or residents, and finally military that occupied it. Fortresses symbolize different things to different people, but they are part of collective identity. Ruins and remains excite feelings of hope despite the fact of its degradation.

Medieval is the age of knights, charwomen, fence and castles. Mostly, our feeling are mixed related to this trace of ancient history and its influence on our present, over lost dreams which can be implied, the end of life, death of civilization, sense of awe and inspiration, intrigue and drama, curiosity, and solitude.

Essential is the question of how to enhance this picture, in authentic, medieval castle, with legends, rivals, aristocrats, army, siege, terror and ruthlessness of medieval siege of warfare, or how to establish sensible connection with the past of vital importance for the story about medieval Bosnia.

How to prevent its further degradation? How to renew romantic revivalism from the eighteenth and nineteenth century? How to emphasize the need that citizens should start to recognize the call of ruins, promenade around the castle ruins, with excitement from the one called "at the first sight?"

Erasing of judgments and created conceptions about fortresses is impossible, but it is possible to emphasize a sense for adventure, explore admiration for the ability of fortresses to survive for centuries.

They survived some destructive actions, as intentionally abandonment, destruction, bombing, sometimes plowing. Ruins are sometimes the only physical evidence of life of that history. Ruins are sensible relics of the past that were formed by modern life (Orbasli [1]).

\section{It is necessary to explore ruins and its role in the history of fortress}

Research mostly includes review of location and review of documentation, heritage, and historical settings, physical and cultural environment. The term:

Definition means critical-historical definition and estimation of resource importance of heritage within its own setting and according to the relevant cultural, social and economic consideration.

Analysis includes examination of the sources using scientific methods, diagnosis of all physical consistency, material, structure, risks, vulnerability and spiritual meaning.

Strategy and implementation of the same includes short and long term plans and programs for preservation and coordination of changes, regular inspections etc.

Cities-fortress of Bosnia and Herzegovina was built during the period of Medieval from XVIII to XV century. Smaller numbers of fortresses were built 
from XII century on the area of central Bosnia which was the core of Medieval Bosnian country.

Medieval is marked as a dark age generally in terms of general socialeconomic development in all cities around the Europe. Although, we should emphasize the fact that Medieval is a period in Bosnia when autonomy of Bosnian state is affirmed.

Analysis of Bosnian and Herzegovina cities, confirmed the presence of different periods of historic development, and that development is related to the fortress also. In the period of medieval, cities-fortress are built on the border of settlements with mountain part where it was possible to control the wider geographical area. Basic parts of most fortresses are defined: yard (fold), walls with the central entrance, cistern, large tower, smaller tower and guards.

During the Medieval, fortresses were built from local stone and the walls were characterized with different thickness and built of crushed stone with binder made of lime mortar. Important objects from this period are holders of area identity, or when it is about the Medieval, then certainly are fortresses (Bobovac, Vranduk, Maglaj fortress and Tešanj fortress) (Vego [2]).

Following the historical development of the cities, we can notice also continuity and variability in urban and architectural development. With the arrival of Ottoman in XV century, in Bosnia, a new way of building of architectural objects appears in accordance with the new philosophy of life in all aspects, but also different upgrades of medieval fortress are adjusted to the new conditions.

Today, most of these cities are in ruins, and it is possible to find some foundation of the city's towers and walls. Based on the current state, level of integrity and authenticity is confirmed. Because of transformation, degradation and other damage during the time, of most Bosnian and Herzegovina cities from the last century, we can discuss some monuments. So, many structures during the time have changed their original appearance (Kudumović [3]).

\subsection{Process of degradation of medieval Bosnian fortress}

Degradation of material is related to the conditions of environment. Mostly, that process will be explained in the following text.

After several years of lack of maintenance, a decayed roof tile becomes slack and it falls. With weakness of connection between mortar and stone, gradual leaching caused by influence of atmospheric and growth of plants begins the process of long term degradation, because the entrance of water is enabled deeply in the structure of wall. Temporary ground flutter also causes the undermining of lower parts of the walls that cause their lean forward. As a result, cracks appear along the wall in most cases. Water is able to infiltrate through unprotected final layer of the wall and deeper in the inner side of the wall over that layer that causes progressive loss of load-bearing stone structure. Further degradation of load bearing structure leads to the collapse and created are mounds of stone and cracks in the ground that under the influence of external factors during the time unite into accumulated remains of ruins. These accumulations of the stone and ground create relatively stable conditions in the 
base of remaining walls. As consequence of the lack of money for temporary protection and further examination of remaining ruins on the location, and after recording of existing location is eventually done, the same very quickly is being sunk into oblivion, at the mercy of different aggressive factors, in the range from environmental influence on ruins of protected buildings to the hunters of souvenirs. Location still provides all information that is considered necessary for detection and diagnosis and insight into the real situation and notification of the same as a report. Almost as a rule, there is lack of funds that can be available for further excavation and the period of remaining begins.

\section{Characteristic damage}

Characteristic damage that can be seen during the implementation of this phase, or a visit to the masonry buildings are: horizontal cracks on the joint of walls and ceiling, cracks in parapets, and on the place of confrontation of cross and facade walls, destruction of external walls out of their plane, cracks under the slope in walls between windows, degradation or partial demolition of the walls or of the whole object, damage with the crushing of stone and fallout of the wall mass from the wall angles and non-bracing walls in loggia.

Specially, unpleasant are cases of discharge of the wall corners, especially separation of outer (load bearing) walls or still its deflection from vertical. This last manifestation can occur partially or along the whole wall.

Leaning and cross tip cracks are explained with unsatisfied, more correctly smaller strength of masonry for acceptance of transverse and main tightening strain caused by influence of seismic forces with variable direction in the plane of wall.

According to these loads of wall strength, primarily it depends on established adhesion between wall elements and mortar. Because that, even where there are small movements in the walls, cracks are formed that usually, follow coupling. That is the reason why the implementation of brittle binders (cement mortar) between wall elements in most regulations is strongly forbidden.

Beside that interpretation and condition, cracks can directly pass through elements of masonry, even if good adhesion in coupling (appropriate class of mortar) is established. This appearance is regularly explained with the weak quality of the wall elements.

Vertical cracks on the area of impact of external longitudinal and transverse internal walls arise as a consequence of common influence of tightening and shearing strains.

\section{Causes of degradation}

Causes of degradation can generally be placed into two basic groups and those are human factors and natural causes. Further separation would be by following:

- Human factor: not maintaining structure of fortress, extracting parts of wall or estrangement from ruins, fire, vandalism and war impacts, lack of original's design etc. 
- Natural causes are for example: impact of rain and water, movement of lower parts of structure, thermal strains and frost, caused by vegetation affection, rodent activity, effect of wind erosion etc.

Humidity is one of the main causes for degradation of material, and it occurs as a result of water infiltration into masonry, caused by condensation of steam from the air, rain that infiltrate through the roof or walls or by groundwater that infiltrates as capillary humidity through foundation. Humidity also depends on porosity of masonry, evaporation and temperature, from the nature of soil, type of foundation, depth of water and cyclical changes of the same. Every material requests defined degree of humidity for its conservation. Surplus of humidity causes for example occurrence of bacteria and fungi. Lack of humidity causes shrinkage of material and it becomes more brittle or sometimes as a dust. Oscillations and sudden changed of humidity are the most dangerous for material because it can activate soluble salts.

Water is one of the main causes for corrosion of embedded stone, decreasing of mechanical strength and in the end its final dissolution and degradation. Often and long-term moisture of stone structures results with stone softening.

Unlike the "water absorption" that indicates on size, and sometimes on character of material porosity, the term "capillary extraction" results as an indicator for speed of capillary water penetration. Because of certain loss of water needed for binding, mortar somehow loses some plastic abilities.

Absorbed water at porous materials significantly affects behavior and material characteristics as it: weakens cohesion between material particles, weakens adhesion between two adjacent elements, weakens resistance of material on frost and affects stability as on aesthetic view of construction.

Presence of efflorescence and crypto efflorescence can be caused by chlorides, sulphates and nitrates. Crystallization of soluble salts in the walls of historical objects causes serious damage of the bases. That is called crystallization or sub florescence. Problems related with the sub florescence can be diagnosed and identified over visual traces, presence of capillary moisture and diagnose of sub florescence can be determined by laboratory examination. In the structure of historical value, there is no presence of just one kind of salt than complex mixture of the same.

After some salts are discovered, there are several methods by which they can be removed. Water for washing, rendering of the surface and surface cleaning of stone, are some of the methods. In the case that the removing of the salts is completed successfully, it is important to prevent the presence of the same. Prevention programs can include a set of restraints for the moisture penetration, chemical injection and coating of the wall with impregnators.

Pollution includes occurrence of the dust and some gases as anhydrous carbonate and sulphur dioxide. This pollution can cause surface corrosion of the stone and metal (bronze, aluminum).

Process of decay for steel elements is mostly evident through presence of corrosion, due to it occurs reduction process of bearing section and increase of volume due to the presence of corrosion when the steel element is embedded into 
masonry, stone or marble, where corrosion causes tearing of the adjacent material.

\section{Analysis of used mortars}

Methods for analysis of mortar can be divided into two wide categories: wetchemical and instrumental. Many laboratories that analyze historical mortars use simple wet-chemical methods with usage of acid, where the sample of mortar is crushed and after it is mixed with the diluted acids. Acid dissolves all carbonates that consist minerals, not only in binders, then also in aggregate, and also any acid soluble materials. There are several variations for the simple test with acid.

One includes gathering of carbon dioxide that is as carbon released in the contact with acid, and based on the amount of gas, content of carbonated mortar can be determined. These methods are fast, cheap and simple for performing, but also given information about original content of mortar is limited on the color and texture of the sand. Methods of collecting gas provide more information about binder than simple acid test.

Instrumental methods of analysis that are used for estimation of mortar are: method of polarized light or light section of microscopy, microscopy for scanning of electron, atomic absorption spectroscopy, diffraction of X-ray, and differential thermal radiation.

All instrumental methods request not only expensive, specialized equipment also specially trained analysts. Meanwhile, instrumental methods can provide much more information about mortar. Thin section with the microscope is possibly the most used instrumental method. Examination of thin slice of mortar on the light is often used as addition to the acid method, especially by examination of aggregate based on carbonate.

Lack of the most methods for mortar analysis is that the causes of mortar with familiar content cannot be analyzed with the aim to determine method for preparation and to determine original proportion of the lime, sand and cement in the mortar. Historical mortars contain widespread local materials in combination based on the decision of the mason.

Industrially produced hydraulic mortar often is not appropriate for the one used in historical objects in our country.

Hydraulic mortar very strongly binds under the water and also on the air. It is produced from red (contains Fe - Ferum) and black stone lime, but assumption is that it could be produced from the white and yellow stone lime. It requests a percentage of $\mathrm{CaCO}_{3}$, in the stone lime from $85-95 \%$. In the case of a large percentage $\mathrm{CaCO}_{3}$ we will not get hydraulic lime, because it will not bind well in the case of humid conditions. Stone lime had to contain also silicates but in the ratio of $5-15 \%$ (clay). In the case that percentage of clay in the stone exceeds $25 \%$, we will not get hydraulic lime, rather than natural cement, that will not bind under the water. With the percentage of clay from $20 \%$ we will get Portland cement. The temperature on which stone lime is burned (necessarily smaller parts) needs to be between 800 and $1350^{\circ} \mathrm{C}$. 
Now in use is quicklime $\mathrm{CaO}$. This kind of lime is clean and has characteristic to reinforce on the air. Slaked lime $\mathrm{Ca}(\mathrm{OH})_{2}$ is not the same as hydraulic lime. Industrial so-called hydraulic lime is not the same as traditional lime mortar and cannot be slaked with the water, because it does not contain free $\mathrm{CaO}$. It is necessary to be melted as cement and like that it is known as ,roman cement". Traditional mortar is made of slaked lime in combination with local sand, mostly in the ratio 1 part of lime with 3 parts of stone per unit volume. Often there are other ingredients such as crushed shells, dust of bricks, clay, natural cement, pigment, even animal hair that is added to improve mortar (Rustempašić [4]).

\subsection{Selection of appropriate mortar mixture}

Repointing is the process of removing damaged or over aged mortar from the masonry joints and its replacement with the appropriate new one. Successful repointing returns visual and physical integrity of masonry buildings. Inappropriately done repointing is not just decreasing the value of building appearance, it can also cause physical damage on the building walls. Decision for repointing is mostly related with some obvious sign of deterioration, for example: decay of mortar, cracks in joints, unstable brick or stone, moist walls or damaged mortar. Analysis requests explanation, taking into account important factors that effect on the state and performance of material, which cannot be determined through laboratory analysis as are: original contain of water, rate of curing, weather conditions in the time of original structure, type of mixing and placing mortar, and cleanliness and condition of sand. The biggest benefit from information that can be reached from laboratory analysis is identification of gradation and color of the sand. These data provide that the color and texture of mortar will be harmonized as much as it is possible, because the part of sand per volume of ingredients is the largest one.

New mortar has to correspond to the historical mortar, in terms of color, texture and volume ratio of ingredients. After laboratory analysis is carried out, it is possible to determine appropriate components of binder and its proportion in historical mortar, of course under the condition that those materials are available Sand has to correspond to the sand contained in historical mortar. New mortar has to have higher permeability and to be tender or even tenderer than historical mortar. Mortar has greater compressive strength than masonry elements, and will not allow moisture migration causing permanent damage of the masonry elements, as are cracking and scaling, that cannot be fixed easily (Čaušević et al. [5]).

\section{Techniques to preserve}

Decision about the way for repair of objects is to proceed by: on-ground and detailed analysis of existing situation, access to the existing technical documentation, verification for integration of provided interventions and reinforcement of existing structure with building outlines, but also 
constructively, or if provided solution appreciates conditions of construction demands related to the purpose. This method, we could say of conceptual consonance of provided interventions with the situation on the ground, helped us to avoid mistakes that could lead to the additional expensive interventions. Decision to intervene in construction has to be consequence of careful evaluation of construction security in the moment when it is analyzed (current state). Scope and the type of intervention have to be balanced with the aim to achieve new level of security. The same kind of problem can be solved on many ways, looking at the same time general projects and specific techniques that we will adopt. Decision about the solving problem for repair and reconstruction of researched fortress depends after all on: seismic zone of location on which fortress is located; type and level of damage, time left for interventions, available equipment, economic criteria and degree of requested safety. Measures that are taken with the aim of protection from earthquake, include improvement of material characteristics (injection and similar), reinforcement of individual elements of structure, reinforcement of foundation or restriction of movements.

Finding a technical solution for repair of structure is a much more complicated and dedicated job than to design a new object, because very often some very important elements of structure cannot be determined before the beginning of the intervention works, when we are faced with the new unknown data that is discovered on the site.

A selection criterion has to be led not only with structural efficiency and economy but also with the knowledge of techniques and technologies used in the construction of monuments and respecting original conception. This aspect together with the part written in the following paragraphs has to be always present in any project concerning preservation of cultural heritage.

\subsection{Repair of demolished wall parts}

Demolished wall surfaces need to be cleaned from binder, depend and to clean joints. After these activities, it is necessary to replace destroyed materials with the new one, or to overbuild walls taking into account about final view of repaired and reconstructed areas in accordance with the current wall area. As a good binder, mortar made of hot lime can be used, eventually lime mortar. Replacement of parts that are missing has to be integrated harmoniously in the whole, but at the same time has to be visibly different from the origin.

When the large surface of the wall is damaged, it is necessary to solve the problem of the binding of a newly reconstructed layer of the wall for existing built mass. This binding will be achieved with partially embedding of longer stone blocks ("anchor stone"), that will be with one part in previously prepared bearing in the wall, and the other part will be placed in the wall paneling (face of the wall).

Also, in most cases, it is necessary to do additional injection of repaired part with lime mortar so the holes would be filled in and achieve strong connection between the wall and fill. This way, greater resistance will be achieved on seismic effects. Between faces of the wall that are built of larger blocks and fill, there is no secure connection that guarantees homogeneous mass of masonry. 
Resistance on the effects of seismic forces for the stone walls is not strong enough because of its binder's lower resistance on straining and shearing, and because of that it is necessary to include some fasteners. Walls are built with the "cap", based on the cement mortar and open joints with injected cement laitance and mortar.

\subsection{Other interventions}

In the case of when the wall is with the damage deeply in the center, with joints without mortar and partially separated from other wall mass, it almost stands free, it is necessary to stop this damage with the anchors made for example of steel reinforcing profiles, that are punctured into wall mass, and on the wall surface pulled through steel sheets with pivot nut, which after the tightening is necessary to pique (nose dive) on installed sheet. Anchors are placed in predrilled holes. After drilling is finished, it is necessary to blow through boreholes, rinse and after setting, it is necessary to suffuse with cement emulsion or epoxides, under the pressure if it is possible or compacting of thin rod made of reinforced steel. For these anchors it is necessary to provide protection against corrosion. Repairs of these walls can be done with the rebuilding if there are available resources.

At some analyzed fortresses, one part of the wall is more swelled with the larger, visible convex surface. It is necessary to reserve this part of the wall with appropriate structure, as soon as possible.

Behind battlement, very often walking paths are located. It is necessary to solve the question of waterproofing and the final layer of this path. Also it is necessary to "block" smaller, visible holes in the wall with the same material or with the stone similar characteristics and appropriate mortar. When we use injection for remediation of cracks, it is necessary first to remove causes that brought the presence of cracks (settlement of foundation soil, or reinforcement of foundations). At inappropriate method of injection, damage can occur for example with the outbreak of blocks under the large pressure during the process of injection, discharge of injection mass on the construction surface etc. Also, damage on the wall can occur on the wall construction, by deficient quality of material for masonry or if material is degraded because of impact of meteorological and other physical and chemical effects. Estimation of injection efficiency can be achieved with the sound testing, endoscopic examination in site, testing of pressure using flat-jacks.

Here will be mentioned also one of the construction segments that cannot be bypassed, especially if we want to determine real condition of structure that is repaired. Those are foundations that represent a very important part of the building structure. Vertical loads of structure are transferred over horizontal entresol structures on the load bearing walls. Finally, these loads are accepted by foundations and dropped on the ground on which structure relies. From this sequence, it is clear that the foundation structures are an important part of object as a unit. Beside vertical loads, foundations have to reliably take the shear forces and the moment of structure tumble (turning over). 
They have to be in compliance with geotechnical characteristics and depth of the solid ground, depth of freezing and those dimensions that will prevent not allowed settlement (and specially uneven) of foundation ground. Direct load transfer from the building to the foundation requests fulfillment of certain assumptions about the soil. Soil has to satisfy requested safety from breakdown, and settlements of the building have to be within allowed limits for ease function of object. If those requests are not fulfilled, properties of foundation soil have to be improved or loads from buildings should be taken into deeper, bearing layers of soil. With the methods for improvement of soil it is necessary to achieve increase of bearing capacity of foundation soil or decreasing or/and acceleration of settlement.

\subsection{Wooden elements in masonry structures}

Structures made of wood, comparing with masonry structures, are preserved in very small amounts till today and represent real rarity in Bosnian Medieval fortresses. This is primarily because of their large sensibility on the impact of micro climate changes. Actually, relative humidity, capacitor that occurs because of lack of ventilation, presence of harmful substances in the air provides development of the mold that causes wood rot. With this kind of degradation, partially are affected also wooden piles, affected by occasional changes of water level, as are also angles of wooden beams, leaning directly on masonry. Termites and worms can also be causes of fast rapid decay of the wood.

If we cut girder poorly before we put it on the appropriate place in structure, it can cause with this method at the wood, that is really anisotropic material, shrinkage, perpendicular to the fibers with forming of cracks along the direction of fiber, that if they are abundant can cause reduction of bearing on shear or in the final consequence of load bearing capacity of structure. Joints between wooden elements are also the areas in which the process of degradation can be emphasized, especially if they are slacked or if there is a presence of stirrup. The best and irreplaceable way of intervention on masonry objects is permanent maintenance. Maintenance includes a group of activities that are conducted during the projected life of the building, with the aim to provide requested reliability.

\section{Results of analysis}

Depending on the degree of fortress structure damage, we classified the damage as the following:

- Smaller damage that do not affect significantly on stability and use of structure and do not interrupt exploration of objects.

- Larger damage - significantly effect on the function and durability of structure, where that the stability of structure is not permanently endangered. 
- Critical damage - where further use of structure is not possible. Those are damage for which repair is economically unreasonable, and in the most of cases it is technically impossible.

Based on the degree of damage, categorization of masonry fortress will be made and those are:

First category: fortresses where are large damage of cover, destruction of architectural verticals (towers, chimneys etc.), presence of larger area of broken mortar on the walls and ceilings, as large number of cracks on partition walls or smaller cracks on load bearing walls.

Second category: buildings with damage of roof structure, partition walls, gable walls, with visible deformation of load bearing elements of roof structure etc.

Third category: at the buildings of this category, there is presence of significant damage of roof structure with large defamation even individual destruction, significant damage of pillars with large numbers of cracks, significant damaged of partition walls, with partial destruction and large deformation.

Fourth category: for these buildings, it is characterized by characteristic appearance of damage of structural elements.

Fifth category: including buildings with completely destroyed structural system (Čaušević [6]).

\section{Conclusion}

Historically, fortresses are much more than fortified military structure. Their function was as political centers from where their owners were controlling large properties that were managed. Most of the fortresses were in a state of degradation, with the parts that ended as embedded in other buildings, on open fields, overgrown with intrusive vegetation as worthless piles or deliberately ignored because of law limitations that forbade private owners to be included into restoration of heritage. Many disappeared, while some still carry past in the stone and mortar, ground works and shot, while diverting attention from the structure and blocking the access to the fortress's parts.

Analyzing physical structure of fortresses, legality is trying to be established and to determine causes of changes near urban fauna, the essence of content and fortress's function, and connections and effects of different factors according to it was formed and transformed in the present time. Different social, technical and technological, geomorphologic, economic and other impacts in common interaction have formed present pictures of the old fortress. Instructions for protection of medieval fortress's heritage and other structures are necessary. It is also necessary to give instructions for valuable historic localities in Bosnia and Herzegovina (Kudumović [3]).

This kind of detailed approach will be part of a comprehensive plan that will consolidate necessary action from determining of value, analysis of historic facts, defining of current state of physical structures and wider scope in which fortresses are located. Detailed analysis of physical condition of preservation and 
definition of physical damage, but also defining the type of traditional structure of these objects, provides that the material is properly selected, type of construction by restoration and reconstruction procedures.

Timely and properly actions of physical preservation will provide function for fortresses and they can be used. This way of comprehensive approach gives basis so the forts and heritage can in general provide sustainable development from the aspect of ecology and culture (Kudumović [3]).

It is necessary to know the original appearance of rubble, how it functioned and similar, with the aim to provide personal experience of the castle or fortress, even rubbles are being left, with the proper treatment in the present time will serve as welfare. Constructors of most fortresses were not wealthy owners, than people with limited resources and lower status that were building smaller fortresses that were appropriate for their special needs and financial limits.

Every fortress should be accepted and recognized because of its individuality, with the history of centuries-old structures, with "foot" of people and women that were born, worked and died in fort and on their properties and that were touching those masonry blocks. Although most of fortresses were built much earlier than cities that were growing around them, today they are affected by urban expansion, hidden behind country shops and residential areas. Some are actually hidden from the views and sometimes it is a challenge to locate fortresses (Kudumović [3]).

\section{References}

[1] A. Orbasli: Architectural Conservation, UK, Blackwell Publishing, 2008.

[2] M. Vego: "Naselja bosanske srednjovjekovne države" Sarajevo, Svjetlost, 1957.

[3] L. Kudumović: "Historical layer of heritage in river Bosnia basin example of Vranduk and its fortress"; The 4th International Conference on Hazards and Modern Heritage: "The Importance of Place", 13-16 June, 2011 in Sarajevo.

[4] N. Rustempašić: "Technological approach and the methods used in AustroHungarian building reconstruction" (including the special overview on the horizontal structures), Faculty of Architecture Sarajevo, Sarajevo, 2004.

[5] A. Čaušević; M. Zečević; N. Rustempašić; L. Kudumović:" Comparison of demands for types and qualities of materials of masonry constructions in time of Vitruvius and today by EC 6"; The 4th International Conference on Hazards and Modern Heritage: "The Importance of Place", 13-16 June, 2011 in Sarajevo.

[6] A. Čaušević: "Structural aspects of repair and reconstruction of masonry building structure", Master degree thesis, completed and published April 2004, Faculty of Architecture Sarajevo, Sarajevo. 